\title{
Reactivity of Municipal Solid Waste Incineration (MSWI) Ashes in a Cementitious Matrix
}

\author{
MR. VIKRAM KUMAR ${ }^{1}$ AND NISHANT GARG ${ }^{2}$
}

\author{
${ }^{1} 2143$, Newmark Civil Engineering Building \\ ${ }^{2}$ University of Illinois at Urbana-Champaign \\ Presenting Author: vikramk3@illinois.edu
}

Supplementary cementitious materials (SCMs) help limit the environmental costs associated with cement production. Routinely employed SCMs - coal fly ash and blast furnace slag are byproducts, and, hence their availability is limited. Further reduction in environmental emissions is only possible by incorporating alternate sources of SCMs in concrete. An alternate SCM found in abundance is Municipal Solid Waste Incineration (MSWI) ash. These ashes are byproducts of the combustion process at a waste-to-energy facility, which can have a composition comparable to ordinary Portland cement, blast furnace slag, and coal fly ash. However, these ashes also have non-trivial concentrations of $\mathrm{Cl}, \mathrm{Pb}, \mathrm{S}, \mathrm{Zn}$, and $\mathrm{Ti}$, which can alter the hydration kinetics of a cementitious matrix. Hence, understanding the influence of MSWI ashes on cement hydration is imperative before its usage. To do so, here we report the hydration behaviour of ordinary Portland cement blended with 8 distinct MSWI ashes. Our results indicate that incorporating these MSWI ashes can either accelerate or retard cement hydration depending upon their composition. Specifically, $\mathrm{Cu}$, $\mathrm{Fe}, \mathrm{Al}, \mathrm{Ti}, \mathrm{Si}, \mathrm{K}, \mathrm{Zn}$, and Sr from the MSWI ash matrix appear to retard cement hydration, while $\mathrm{Pb}, \mathrm{Br}, \mathrm{S}, \mathrm{Ca}$, and $\mathrm{Cl}$ appear to accelerate cement hydration. Based on these results, we introduce a new parameter - Incineration Ash Coefficient $\left(\mathrm{I}_{\mathrm{AC}}\right)$ which correlates with the 7-day compressive strength of mortars incorporating MSWI ashes reasonably well $\left(\mathrm{R}^{2}=0.82\right)$. These results highlight element-specific influence on the hydration kinetics of ordinary Portland cement, which is critical for selectively employing incineration ashes as supplementary cementitious material.

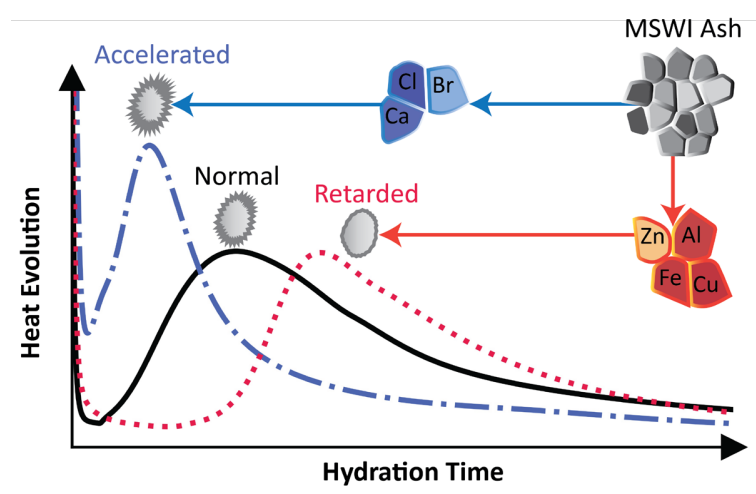

